\title{
CIÊNCIA DA INFORMAÇÃO: DENOMINAÇÃO DE CURSO E DIRETRIZES CURRICULARES
}

\author{
Maria Odila FONSECA ${ }^{1}$
}

RESUMO

Discussão das especificidade da Ciência da informação e da Arquivologia e de suas relações interdisciplinares.

Palavras-chave: Ciência da Informação; Arquivologia; Interdisciplinaridade.

\begin{abstract}
This paper discusses the boundaries of two disciplines (Information Science and Archival studies) and aspects of their interdisciplanarity.
\end{abstract}

Key words: Information Science; Archival Studies; Interdisciplinarity.

\section{O PROBLEMA}

As afirmações em torno das características interdisciplinares da Ciência da Informação têm estado presente na maior parte dos estudos que objetivam aprofundar as reflexões em torno das características desta disciplina específica. Pinheiro afirma:

"Durante vinte anos de estudos de Ciência da Informação nossa percepção é de que a ciência da Informação tem seu estatuto científico, como ciência social que é, portanto, interdisciplinar por natureza, e apresenta interface com a Biblioteconomia, Ciência da Computação, Ciência Cognitiva, Sociologia da Ciência e Comunicação, entre outras áreas..." (1997,p.1)

Jardim \& Fonseca (1992) apresentam quadro síntese ilustrativo das principais relações interdisciplinares observadas por importantes pensadores da Ciência da Informação:

\begin{tabular}{|l|l|}
\hline \multicolumn{2}{|c|}{$\begin{array}{c}\text { Relações da Ciência da Informação } \\
\text { com outras Disciplinas }\end{array}$} \\
\hline SARACEVIC & $\begin{array}{l}\text { Biblioteconomia, Ciência da Computação, } \\
\text { Ciência Cognitiva, Comunicação. }\end{array}$ \\
\hline BELKIN & $\begin{array}{l}\text { Lingüistica, Comunicação, Ciência da } \\
\text { computação, Estatística, Biblioteconomia. }\end{array}$ \\
\hline LE COADIC & $\begin{array}{l}\text { Psicologia, Lingüística, Sociologia, Informática, } \\
\text { Matemática, Lógica, Estatística, Economia, } \\
\text { Direito, Politica, Filosofia. }\end{array}$ \\
\hline FOSKET & $\begin{array}{l}\text { Biblioteconomia, Ciência da Computação, } \\
\text { Psicologia, Lingüistica. }\end{array}$ \\
\hline SOEMEN & $\begin{array}{l}\text { Semiologia, Lingüistica, Administração, } \\
\text { Lógica, Psicossociologia, Informática }\end{array}$ \\
\hline SHERA & Biblioteconomia \\
\hline
\end{tabular}

A evidente exclusão da Arquivologia como disciplina com a qual estes autores possam identificar elementos comuns à Ciência da Informação é instigante. Tais relações parecem "a olho nu", bastante óbvias, se considerarmos, na perspectiva que

1. Professora do Curso de Ciência da Informação da Universidade Federal Fluminense (UFF). 
Heckhausen (1972) identifica como o domínio material, o conjunto de objetos das quais elas se ocupam: a informação.

E esta exclusão é mútua, pois a Arquivologia não tem considerado a Ciência da Informação como área afim, fato que pressupõe-se estreitamente vinculado a não consideração da informação como seu objetivo preferencial de estudo.

Alguns exemplos deste pensamento ainda hegemônico podem ser citados a partir de alguns formadores de opinião na área arquivística. Jardim elenca exemplos de definições de Arquivologia nos planos nacional e internacional:

"Delmas analisou o tema sob uma perspectiva francesa. Para ele, a Arquivologia é 'a ciência que estuda os princípios e os procedimentos metodológicos empregados na conservação dos documentos de arquivos, permitindo assegurar a preservação dos direitos, dos interesses, do saber e da memória das pessoas fisicas $e$ morais'

Para o arquivista argentino Vasquez (1994) 'a Arquivologia ou a Ciência da Administração de Documentos e Arquivos é um campo de saber cujos objetos de estudo são: os documentos de arquivo e a archivalia (os conjuntos orgânicos dos documento); os arquivos e os sistemas de arquivos; os arquivistas e as associações de arquivistas.'

Na Terminologia Arquivistica sistematizada por colegas portugueses (1996), não consta o termo Arquivologia. Neste caso, Arquivistica é 'a disciplina que estuda os princípios teóricos e práticos do funcionamento do Arquivo do tratamento dos seus fundos'.

Para Esposel (1968), a Arquivologia é 'uma disciplina auxiliar da administração e da história, que se refere a criação histórica, organização e função dos arquivos e seus fundamentos legais ou jurídicos', ...Em 1980, uma Comissão de Estudo de Arquivologia, no âmbito da ABNT (apud PAES, 1991) define
Arquivologia como 'princípios e técnicas a serem observados na constituição, organização, desenvolvimento e utilização dos arquivos'.

Para Moraes e Castro (1995) 'Arquivologia é a ciência dos Arquivos. É o complexo de conhecimentos teóricos e práticos relativos à organização de arquivos e às tarefas do arquivista." (1996, pp. 3-4 e 8)

Assim, a informação não tem sido considerada como objeto privilegiado da Arquivologia, aparecendo, na literatura clássica da área, como uma consequêencia do documento de arquivo, que, por sua vez, é visto como um elemento do arquivo. "Importa muito que não percamos de vista a tríplice dimensão do objeto da Arquivologia e sua ordem (grifo nosso): arquivos - documentos de arquivo - informação." (HEREDIA, 1993, p.32)

Os indícios de uma possibilidade renovadora em relação a este pensamento hegemônico tem surgido em universidades norte-americanas e canadenses, notadamente entre os estudiosos relacionados com a Escola de Biblioteconomia e Ciências da Informação da Universidade de Montreal - ESBI, que criaram, em 1987, o Grupo Interdisciplinar de Pesquisa em Arquivologia - GIRA, fruto e semente desse processo de renovação, estimulando a produção de pesquisa sobre a Arquivologia e seus objetos. Inaugura-se, assim, um importante espaço de reflexão em torno das especificidade do fenômeno informacional arquivístico e na busca da construção de um conceito de informação arquivística.

"Ao final de uma evolução transformadora de sua missão e definição, a Arquivologia aparece, hoje, como uma disciplina cujo razão de ser situa-se no seio da gestão da informação, recurso vital das organizações ... Todos os membros da organização tem necessidade de informação para cumprir suas funções respectivas. As informações necessárias serão buscadas no interior ou no exterior da 
organização. Estas informações podem ser verbais ou registradas sobre suportes como, por exemplo, o papel, a fita magnética, o disco ótico ou o microfilme. Podem ser orgânicas, quer dizer, elaboradas, expedidas ou recebidas no quadro das funções do organismo ou não orgânicas, quer dizer, produzidas fora do quadro das funções do organismo... as informações registradas orgânicas nascem no arquivo do organismo" (grifo nosso) (COUTURE, DUCHARME, ROSSEAU, 1988, pp. 53-54)

$\mathrm{Na}$ Europa são menos visíveis os indícios de rompimento com as práticas tradicionais a que se referem este projeto. Apesar disso, é interessante observar o quadro analisado por Jardim:

"Em 1990, a Universidade de Maccerata,... promoveu uma conferência internacional sob o tema "A Ciência Arquivística no limiar do Ano 2.000", (...) Delmas analisou o tema sob uma perspectiva francesa (...) contempla-nos ainda com algumas questões interessantes:

(...) temos ainda uma Arquivologia exclusivamente ciência auxiliar da história; como tal, a Arquivologia deve-se emancipar da História sem cair sob a proteção das ciências da informação;(...) o desenvolvimento da Arquivologia tem sido confrontado com alguns elementos: a estreiteza do domínio da atividade da profissão (predominante no setor público), de sua organização, de sua imagem, de seus efetivos;(..) a Arquivologia é uma ciência? É uma questão em aberto, mas os arquivos tem necessidade hoje de uma verdadeira ciência.

No mesmo evento, Heredia analisa a área sob a perspectiva espanhola (...) nasce no século XIX como o nome de Arquivologia, com caráter fortemente historicista; o documento ocupava então a atenção dos profissionais, não os arquivos (...) A Arquivologia do século XX seria cientifica, diferenciada da Arquivologia do século XIX, distinta de outras disciplinas, contando atualmente com um objeto, um método e uma linguagem própria (ainda que por consolidar)." (1996, p.3)

No Brasil observa-se, nos anos 90, um crescente interesse dos pesquisadores da área arquivística pelos programas de pós graduação em Ciência da Informação, interesse que vem se desenvolvendo numa relação de reciprocidade, da qual pode ser considerado emblemático o prêmio recebido por José Maria Jardim com uma tese cujo objeto é a informação arquivística.

A partir destas colocações necessárias, gostaria de apresentar alguns pontos para provocar o debate:

- Está longe de ser consenso na área Arquivística a questão da Informação como seu principal objeto de estudo, menos ainda que a Arquivologia faça parte de um grupo de Ciência da Informação;

- Em relação à Ciência da Informação, a proposta do MEC sugere uma postura "pretensamente aglutinadora", fato que não é sequer sugerido na literatura fundadora da área. Pelo contrário, a Ciência da Informação tende, nas suas concepções clássicas, a não considerar a Arquivologia e a Museologia como áreas afins. A reunião dos 3 cursos sob esta área comum foi feita à revelia da mesma, surgindo como fato dado nos documentos do MEC. Em que pesem quaisquer possibilidade de enxergarmos aspectos comuns nas três áreas, e entre estas e a Ciência da Informação, a justificativa apresentada é insuficiente para esclarecer o pensamento que está por trás da decisão do MEC de reuni-las sob a área da Ciência da Informação.

\section{REFERÊNCIAS BIBLIOGRÁFICAS}

COUTURE. C. e ROUSSEAU, J.Y. Les Archives au XX siècle. Montreal:Université de Montreal.1982.

COUTURE. C. e ROUSSEAU, J.Y. L'archivistique a-t-elle trouvé son identité? Argus. Montreal, v. 17, n. 2, junho 1988 . 
GIRA. La place de I"' archivistique dans la gestion de I"informations: perspectives de recherche. Montreal: Ministaire des Affaires Culturelles/ Archibves Nationales du Quebec, 1990.

HEREDIA, A.Herrera. Archivística General. Teoria y Práctica. Sevilha: Servicio de Publicaciones de la Diputación de Sevilla, 1983.512p.

JAPIASSU, Hilton. Interdisciplinariedade e Patologia do Saber. Rio de Janeiro: Imago, 1976.

JARDIM, José Maria. O papel do arquivista como produtor de conhecimento. XI Congresso Brasileiro de Arquivologia. Associação dos Arquivistas Brasileiros. Rio de Janeiro. 1996.
JARDIM, José Maria \& FONSECA, Maria Odila. As relações entre a Arquivística e a Ciência da Informação. Lisboa, Cadernos BAD, v. 2, 1992.

JARDIM, José Maria \& FONSECA, Maria Odila. Ciência da informação e Interdisciplinariedade. Monografia apresentada ao final da disciplina de Metodologia da Pesquisa. Curso de Mestrado em Ciência da Informação. UFRJ/IBICT. 1992.

PINHEIRO, Lena Vânia R. A Ciência da Informação entre a luz e a sombra: domínio espistemológico e campo interdisciplinar. Tese de Doutorado. Doutorado em Comunicação. UFRJ/ECO. 1997. 